\title{
Muses et nymphes au XIX siècle, études réunies et présentées par Eric Francalanza
}

\section{Catherine Thomas}

\section{OpenEdition}

\section{Journals}

\section{Édition électronique}

URL : http://journals.openedition.org/studifrancesi/3756

DOI : 10.4000/studifrancesi.3756

ISSN : 2427-5856

\section{Éditeur}

Rosenberg \& Sellier

\section{Édition imprimée}

Date de publication : 1 décembre 2012

Pagination : $575-576$

ISSN : 0039-2944

\section{Référence électronique}

Catherine Thomas, "Muses et nymphes au $x x^{e} x^{e}$ siècle, études réunies et présentées par Eric

Francalanza », Studi Francesi [En ligne], 168 (LVI | III) | 2012, mis en ligne le 30 novembre 2015, consulté le 05 mars 2021. URL : http://journals.openedition.org/studifrancesi/3756 ; DOI : https:// doi.org/10.4000/studifrancesi.3756

Ce document a été généré automatiquement le 5 mars 2021.

\section{(c) (i) (9) $\Theta$}

Studi Francesi è distribuita con Licenza Creative Commons Attribuzione - Non commerciale - Non opere derivate 4.0 Internazionale. 


\title{
Muses et nymphes au XIX siècle, études réunies et présentées par Eric Francalanza
}

\author{
Catherine Thomas
}

\section{RÉFÉRENCE}

AA. VV., Muses et nymphes au XIX ${ }^{e}$ siècle, études réunies et présentées par Eric FRANCALANZA, Presses universitaires de Bordeaux, «Eidôlon», n 95, 2011, pp. 218.

1 Ce cahier réunit les actes du $5^{\mathrm{e}}$ colloque organisé en juin 2008 par le laboratoire pluridisciplinaire de Recherches sur l'Imaginaire et le CELIS de Clermont II. L'introduction, par Eric FRANCALANZA (Le sort des Muses au XIX siècle: histoire d'un abandon?, pp. 7-16) souligne les enjeux à la fois historiques et esthétiques du sujet.

2 La première partie «Le poète et sa (ses) muse(s)» envisage les transformations de la muse et ses rapports avec le poète. Marie-Catherine HUET-BRICHARD ( $L a$ muse et le poète: héritages et ruptures, pp. 19-30) montre comment les métamorphoses de la figure de la muse mettent en évidence l'évolution des rapports que le poète entretient avec la poésie. D'abord garante d'une appartenance à une poésie élective, la muse se fait, avec l'époque romantique, le reflet d'un poète dans sa singularité. S'il traduit un mouvement inéluctable vers une façon toute romantique de se penser et d'envisager le monde et l'art, le passage de la muse classique, sublime, intemporelle, à la muse moderne, libre, parfois triviale, ne se fait pas sans douleur, ni sans renoncements. Ce processus de démythification progressive se retrouve dans la communication de Lise SABouRIN ( $D u$ devenir de la sylphide au XIXe siècle, pp.31-46), qui s'intéresse à la figure fluide et évanescente de la sylphide, depuis les fantaisies du xvIII siècle jusqu'aux contes mallarméens. À la fois aérienne, mystérieuse, et terrestre, la sylphide se prête à merveille à l'incarnation de la femme idéale, inaccessible, jusqu'à ce qu'elle devienne cliché soumis à l'ironie d'écrivains marqués par le désenchantement. Dans les deux 
articles suivants, la muse est bien humaine: soit elle prend corps, ainsi que le révèle Suzel ESQUIER (Stendhal et ses cantatrices, pp. 47-56), dans la cantatrice telle que la perçoit Stendhal; soit elle devient, selon Yolande LEGRAND (Une muse postérieure à l'Éva de "la Maison du berger", pp.57-64), égérie, femme aimée, sous les traits de la comtesse Kossakowska, figure de l'inspiration pour Vigny. Corinne BAYLE (Nerval, Gautier et la Vénitienne de Gozzi: l'invention d'un mythe fraternel, pp. 65-74) montre comment la quête de la «blonde aux yeux noirs», muse fantomatique rêvée à partir d'une expression du dramaturge italien Gozzi, à laquelle se superposent des représentations poétiques et picturales, révèle des postures esthétiques différentes. Si cette figure féminine signifie d'abord, pour les deux écrivains, la supériorité de l'art sur la nature, elle devient chez Nerval un idéal inaccessible, tandis que Gautier tente de faire coïncider le rêve avec le réel, confrontant ironiquement «l'esthétique à la réalité concrète».

3 La deuxième partie s'intitule «Imag(inair)es de la muse». Confrontant plusieurs textes sources, Anne-Marie BARON explore la présence cachée de Mélusine, muse occulte de Balzac (pp. 77-85), dans Clotilde de Lusignan ou le beau juif et Le Succube. Mettant au jour des motifs tant autobiographiques que fantasmatiques, cette figure ambiguë et polysémique se retrouve à travers de nombreux personnages féminins de La Comédie humaine, dont elle éclaire la dimension ésotérique et mystique. Yvon LE SCANFF se livre à une étude sur La figure ambivalente de la reine Mab (pp. 87-102) dans quelques romans sandiens à partir d'une ballade de George Sand parue en 1832. Chez l'écrivain, cette figure issue des légendes celtiques se fait frêle sylphide, diane dominatrice ou muse poétique, se révélant ainsi «constitutive d'une représentation typique et romanesque de l'héroïne sandienne». Éternelle figure de l'Autre, elle est source d'inspiration et d'illusion, relais vers l'idéal, à la fois désirée et obstacle au désir. François KeRLougan (Inspiration et spiritisme: forme et fonction de la muse dans "Spirite" de Gautier, pp. 103-112) montre que si le personnage de Spirite s'apparente en de nombreux points à la muse traditionnelle, pure allégorie qui initie le poète aux mystères de la création et lui révèle un monde idéal, elle peut également apparaître comme une femme réelle par le biais du fantastique et du spiritisme. À travers elle, Gautier met ainsi en scène un dilemme tant esthétique qu'érotique: «peut-on représenter l'idéal, la beauté, sans courir le risque de les voir déchoir?». L'article suivant nous transporte vers une autre culture: François LEGRAND se penche sur la naissance de la muse démocratique (pp. 113-120) américaine à travers l'exemple de deux peintres, Samuel Morse et William Sydney Mount qui, chacun à leur manière, témoignent de l'émergence d'un art typiquement américain, qui intègre l'idée de démocratie.

La troisièmes partie («Muses et nymphes: questions sur l'art»), s'ouvre sur une étude d'Eric FRANCALANZA (pp. 123-134) qui évoque le processus de cristallisation pour saisir la dématérialisation progressive de l'héroïne du roman de Mme de Krüdener, Valérie, sous le regard de l'épistolier Gustave. Si Valérie se rapproche de la muse, c'est qu'elle tend à incarner une conception de l'art mise en œuvre dans le roman qui, entre imitation et invention, découvre la portée esthétique de l'imagination. C'est encore à travers l'étude de lettres, celles qu'échangent les deux protagonistes d'Adolphe, de Benjamin Constant, que Monique VERRET (Maîtresse ou muse?, pp. 135-140) fait apparaître un visage peu traditionnel de la muse: celui d'Ellénore, dont l'image suscite la création littéraire, mais qui perd son pouvoir au moment même où elle accepte son rôle. Dans une perspective comparatiste cette fois, Thomas BUFFET (pp. 141-176), à travers la représentation que les poèmes de Friedrich Hölderlin et André Chénier offrent de la muse, saisit le rapport 
que ces deux écrivains entretiennent avec le classicisme et le romantisme. Romain VIGNEST (Les nymphes hugoliennes: entre récréation et contemplation, pp. 177-186) retrouve l'héritage, rarement revendiqué par les écrivains romantiques, d'Horace et de Virgile dans les figures de nymphes qui peuplent les Odes, où elles soulignent en particulier l'aspect érotique de la voyance hugolienne. S'intéressant aux Muses originelles dans l'œuvre de Renée Vivien (pp.187-193), Marie-Ange BARTHOLOMOT-BESSOU analyse la façon dont l'écrivain intègre la présence de muses anciennes, dont elle s'inspire et qu'elle réinvente, pour mieux affirmer son identité, son imaginaire et sa conception, toute féminine, de l'écriture. Le motif de la nymphe est bien encore source de création au début du Xx ${ }^{e}$ siècle, comme le précise Agnès LHERMITTE (pp. 195-206): L'Après-Midi d'un faune de Mallarmé inspire le chorégraphe Nijinsky qui offre une approche toute moderne de ce personnage mythique. En explorant l'évolution et les diverses significations de la muse, cet ouvrage permet d'approcher dans ses nuances la façon dont le $\mathrm{XIX}^{\mathrm{e}}$ siècle littéraire revisite la tradition classique pour l'inscrire dans la modernité. 